\title{
EDUCATION AND THE PREVENTION OF POSTURAL DEFECTS
}

doi: 10.1515/humo-2015-0011

\author{
AGNIESZKA OLCHOWSKA-KOTALA ${ }^{1}$, KRYSTYNA CHROMIK ${ }^{2}$ \\ ${ }^{1}$ Wrocław Medical University, Wrocław, Poland \\ ${ }^{2}$ University School of Physical Education, Wrocław, Poland
}

\begin{abstract}
Purpose. The aim of this study was to determine: whether and at what stage of education is proper body posture learned, the intention of young adults to participate in activities teaching proper posture, and the effects of factors related with the said intention. Methods. The study involved 430 university students aged 18-24 years. Anthropometric data was collected. Participants completed questionnaires assessing physical activity level (IPAQ) and their intention to participate in extracurricular activities teaching proper posture while sitting or walking, proper running technique, corrective gymnastics, or weight loss exercises. A self-assessment of posture, physical fitness, attractiveness, and body satisfaction was also completed. Results. Lower back pain was experienced by $41 \%$ of the respondents. Most were taught proper posture-related habits in primary school, followed by secondary school, and then at university. Many students expressed their intention to participate in the extracurricular activities. None of the questionnaire variables were associated with the intention to learn proper walking posture or proper running technique. The intention to participate in classes teaching proper sitting posture was associated with lower back pain in women and low physical activity level in men. In women, a relationship was found between the intention to participate in weight loss exercises and body dissatisfaction, high BMI, and poor self-evaluations of posture and attractiveness. In men, this activity was associated with body dissatisfaction. Conclusions. There is a need for further education on the development of proper postural habits at the university level.
\end{abstract}

Key words: education, body posture, body satisfaction, BMI

\section{Introduction}

Many studies are concerned with self care today. Their authors emphasize the need of increasing physical activity, paying attention to diet, and maintaining a healthy body weight in all age groups. More and more prevention programs have been introduced to encourage such healthy behavior. This is both due to real-life needs and the increasing recognition of the importance of lifestyle on health. Increased sedentary behavior has led to people spending large amounts time in a sitting position. Mechanical equipment, vehicles, and other forms of technology have made life easier at the cost of a lazier and less active population. It can be argued that life in the $21^{\text {st }}$ century has begun to deviate from the evolutionary path set out for us by nature.

Among the appeals for improved self care, more and more attention is being paid to the development of good posture. Incorrect posture in everyday activities of life contributes to back pain, especially in the lower back. Pain in the lumbar region of the spine is a serious problem in developed countries. It is estimated that between $60 \%$ and $80 \%$ of the population experiences lower back pain at some point in life [1]. To effectively combat this phenomenon, we need to be aware of the relationship between back pain and how everyday activities are per-

\footnotetext{
* Corresponding author.
}

formed. We need to know how to properly perform these activities and how to exercise and strengthen associated muscle groups based on adopted kinesitherapeutic principles. This also includes restoring joint mobility, if impaired. Although a number of educational programs addressing back pain and proper posture have been enacted in schools, they seem to be insufficient. Recent studies have indicated that an increasing number of children and adolescents experience back pain [2]. Interventions in childhood were found to be ineffective [3], hence the need for educating people on how to properly take care of their bodies even at later stages of life. Only such continuing education can consciously change healthrelated habits. The psychological models used to describe the behavioral changes needed to develop healthy habits often stress the concept of intention. Although several studies found that formulating intention does not ultimately lead to behavioral changes [4], it is still a crucial factor in taking action.

Based on the above considerations, the aim of this study was to determine (1) whether and at what stage of education did the participants learn about proper sitting and walking posture and also proper running technique (2) whether young adults are willing to participate in extracurricular activities aimed at correcting posture in sitting, walking, or running or other healthrelated goals, and (3) what factors are associated with the intention to participate in the suggested extracurricular activities. 
A. Olchowska-Kotala, K. Chromik, Education and the prevention of postural defects

\section{Material and methods}

The study involved 430 environmental and life science university students aged $18-24$ years (309 women and 121 men). Participation in the study was voluntary. Body height and mass were recorded. Participants completed the International Physical Activity Questionnaires (IPAQ), a questionnaire on their intention to participate in extracurricular activities associated with correcting posture and health, and a self-assessment on posture, physical fitness, body satisfaction, and attractiveness. The study was approved by the local ethics committee and conducted in October 2012 during the participants' physical education classes in accordance with the Declaration of Helsinki.

Anthropometric measurements were made in accordance with accepted procedures using calibrated equipment; measurement error was limited to $1 \%$. Body mass was measured using a portable Seca 761 scale (Seca, Germany) with an accuracy of $0.1 \mathrm{~kg}$. Body height was measured using a Posturometer S (Posmed, Poland) with an accuracy of $0.1 \mathrm{~mm}$. During measurement the participants stood upright with their feet together and head in the Frankfort horizontal plane while unshod and dressed in gym clothes.

Body mass index (BMI) was calculated by dividing body weight $(\mathrm{kg})$ with body height $\left(\mathrm{m}^{2}\right)$. BMI [5] was classified into four categories: underweight $(<18.5)$, normal (18.5-24.9), overweight (25-29.9), and obese (>30).

The Polish version of the IPAQ Short Form was administered [6]. All procedures delineated by the IPAQ scientific committee were followed. Physical activity was estimated based walking and moderate and intensive physical activity. Total energy cost and therefore the physical activity level (PA) of each respondent was calculated by multiplying exercise frequency and duration by its corresponding intensity to determine the Metabolic Equivalent of Tasks (MET), a metabolic measure corresponding to oxygen consumption at rest. The IPAQ describes PA in MET min/week; this value was used to distinguish three levels of intensity: low, moderate, and high. The participants were asked to indicate where (primary school, secondary school, university, at home) they were educated about proper sitting posture, proper walking posture, and proper running technique. Respondents were allowed to select more than one source.

Intention to participate in extracurricular activities was assessed with the question, "Would you like to participate in extracurricular activities teaching: (a) proper sitting habits, (b) proper walking posture, (c) proper running technique, (d) corrective gymnastics, or (e) weight-loss exercises?" Respondents answered with a "yes" or "no". Information on the incidence of low back pain within the past year was also collected by using a "yes" or "no" question.

Respondents were asked to evaluate their body posture. Responses were ordered on a 7-point scale from 1 (very correct) to 7 (very incorrect). This included a selfassessment of body satisfaction, physical fitness, and attractiveness, where the responses were also scaled using a 7-point scale from 1 (very negative position) to 7 (very positive position). The 7 levels were then simplified into three response categories: "positive", "I have no opinion", and "negative". The response "I have no opinion" was based on a response level 4 as the neutral option; the remaining response levels were accordingly grouped.

Statistical analysis was performed with SPSS ver. 18 (PASW, USA). Descriptive statistics were calculated for all variables. The chi-square test was used to establish any relationships between the intention to participate in the extracurricular activities (on proper posture while sitting, walking, and running; corrective gymnastics; and weight loss) and the questionnaire variables. Analyses were performed separately for men and women. Statistical significance was set at $p \leq 0.05$.

\section{Results}

As shown in Table 1, the majority of the participants fell within normal ranges. More were underweight than

Table 1. Descriptive statistics characterizing the respondents (as mean $\pm S D$ and percent response)

\begin{tabular}{|c|c|c|}
\hline & \\
\hline & Women & Men \\
\hline BMI & $21.78 \pm 13.89$ & $23.60 \pm 7.15$ \\
\hline Underweight & $16 \%$ & $6 \%$ \\
\hline Normal & $73 \%$ & $65 \%$ \\
\hline Overweight & $7 \%$ & $22 \%$ \\
\hline Obese & $4 \%$ & $7 \%$ \\
\hline IPAQ PA & $3877 \pm 3662$ & $5843 \pm 4927$ \\
\hline Low & $8 \%$ & $3 \%$ \\
\hline Average & $45 \%$ & $23 \%$ \\
\hline High & $47 \%$ & $74 \%$ \\
\hline Posture & $3.98 \pm 1.34$ & $3.88 \pm 1.60$ \\
\hline Positive & $35 \%$ & $38 \%$ \\
\hline I have no opinion & $26 \%$ & $18 \%$ \\
\hline Negative & $39 \%$ & $44 \%$ \\
\hline Body satisfaction & $4.51 \pm 1.33$ & $5.14 \pm 1.23$ \\
\hline Positive & $54 \%$ & $75 \%$ \\
\hline I have no opinion & $25 \%$ & $16 \%$ \\
\hline Negative & $21 \%$ & $9 \%$ \\
\hline Physical fitness & $4.43 \pm 1.29$ & $5.37 \pm 1.16$ \\
\hline Positive & $49 \%$ & $82 \%$ \\
\hline I have no opinion & $30 \%$ & $14 \%$ \\
\hline Negative & $21 \%$ & $4 \%$ \\
\hline Attractiveness & $4.51 \pm 1.24$ & $5.06 \pm 1.21$ \\
\hline Positive & $53 \%$ & $68 \%$ \\
\hline I have no opinion & $28 \%$ & $25 \%$ \\
\hline Negative & $19 \%$ & $7 \%$ \\
\hline
\end{tabular}


Table 2. Prevention of postural defects at different stages of education

\begin{tabular}{llr} 
& \multicolumn{2}{l}{ Stage of education } \\
\cline { 2 - 3 } Proper sitting posture & Primary school & $87 \%$ \\
& Secondary school & $31 \%$ \\
& University & $14 \%$ \\
& Home & $84 \%$ \\
\hline \multirow{2}{*}{ Proper walking posture } & Primary school & $70 \%$ \\
& Secondary school & $22 \%$ \\
& University & $7 \%$ \\
& Home & $75 \%$ \\
\hline \multirow{2}{*}{ Proper running technique } & Primary school & $38 \%$ \\
& Secondary school & $33 \%$ \\
& University & $7 \%$ \\
& Home & $20 \%$ \\
\hline \multirow{2}{*}{ Corrective gymnastics } & Primary school & $57 \%$ \\
& Secondary school & $3 \%$ \\
& University & $2 \%$ \\
\hline
\end{tabular}

Table 3. Intention to participate in extracurricular activities

\begin{tabular}{lcc}
\hline Extracurricular activity & Women & Men \\
\hline Proper sitting posture & $28 \%$ & $20 \%$ \\
Proper walking posture & $39 \%$ & $32 \%$ \\
Proper running technique & $38 \%$ & $39 \%$ \\
Corrective gymnastics & $35 \%$ & $25 \%$ \\
Weight loss exercises & $62 \%$ & $28 \%$ \\
\hline
\end{tabular}

obese and overweight combined. Among men, the majority had BMI above 24.9 while only $6 \%$ were classified as underweight.

The majority of the respondents indicated that they learned proper posture and running technique in primary school $(87 \%$ - sitting posture, $70 \%$ - walking posture, $38 \%$ running technique; Table 2). This was then followed by secondary school (31\% - sitting, 22\% - walking, 33\% - running technique) and then at university (14\% - sitting, $7 \%$ - walking, $7 \%$ - running technique). Approximately $41 \%$ of the sample experienced low back pain. Corrective gymnastics classes had been attended by $2 \%$ of the respondents at the university level.

Many of the respondents expressed their intention to participate in the suggested extracurricular activities (Table 3). However, none of the questionnaire variables were associated with the intention to participate in activities teaching proper walking posture or proper running technique (Tables 4 and 5). In women, a relationship between the intention to participate in classes on proper sitting posture and lower back pain was found. In men, the intention to participate in classes on proper sitting posture was associated with low PA. A relationship was found in women between the intention to participate in weight loss activities and high BMI and a low self-evaluation of body satisfaction, posture, and attractiveness. In men, the intention to participate in weight loss activities was associated only with body dissatisfaction.

Analysis between the women and men on their intention to participate in the suggested extracurricular activities showed that significantly more women expressed their intention to take part in activities aimed

Table 4. Intention to participate in extracurricular activities among the female respondents $(n=309)$

\begin{tabular}{|c|c|c|c|c|c|c|c|}
\hline & $\begin{array}{c}\text { BMI } \\
\chi^{2} \mathrm{df}(3)\end{array}$ & $\begin{array}{l}\text { PA level } \\
\chi^{2} \mathrm{df}(2)\end{array}$ & $\begin{array}{l}\text { Posture } \\
\chi^{2} \mathrm{df}(6)\end{array}$ & $\begin{array}{l}\text { Back pain } \\
\chi^{2} \mathrm{df}(1)\end{array}$ & $\begin{array}{l}\text { Physical fitness } \\
\qquad \chi^{2} \operatorname{df}(6)\end{array}$ & $\begin{array}{l}\text { Attractiveness } \\
\chi^{2} \operatorname{df}(6)\end{array}$ & $\begin{array}{c}\text { Body satisfaction } \\
\chi^{2} \operatorname{df}(6)\end{array}$ \\
\hline Sitting & 0.633 & 6.858 & 8.626 & $5.916^{*}$ & 4.945 & 6.095 & 2.131 \\
\hline Walking & 3.048 & 5.504 & 5.785 & 3.163 & 4.250 & 2.808 & 3.839 \\
\hline Running & 0.168 & 0.480 & 2.389 & 1.952 & 7.779 & 4.617 & 10.343 \\
\hline $\begin{array}{l}\text { Corrective } \\
\text { gymnastics }\end{array}$ & 4.449 & 5.192 & $17.874 *$ & 0.728 & 3.580 & 4.387 & 3.293 \\
\hline Weight loss & $21.853^{* *}$ & 0.492 & $16.587^{*}$ & 0.216 & 7.413 & $15.387^{*}$ & $35.015 * *$ \\
\hline
\end{tabular}

$* p \leq 0.05, * * p \leq 0.001$

Table 5. Intention to participate in extracurricular activities among the male respondents $(n=121)$

\begin{tabular}{|c|c|c|c|c|c|c|c|}
\hline & $\begin{array}{c}\text { BMI } \\
\chi^{2} \mathrm{df}(3)\end{array}$ & $\begin{array}{c}\text { PA } \\
\chi^{2} \mathrm{df}(2)\end{array}$ & $\begin{array}{l}\text { Posture } \\
\chi^{2} \mathrm{df}(6)\end{array}$ & $\begin{array}{l}\text { Back pain } \\
\chi^{2} \operatorname{df}(1)\end{array}$ & $\begin{array}{l}\text { Physical fitness } \\
\qquad \chi^{2} \mathrm{df}(5)\end{array}$ & $\begin{array}{l}\text { Attractiveness } \\
\quad \chi^{2} \operatorname{df}(6)\end{array}$ & $\begin{array}{l}\text { Body satisfaction } \\
\qquad \chi^{2} \mathrm{df}(5)\end{array}$ \\
\hline Sitting & 6.146 & $4.116^{*}$ & 3.179 & 0.051 & 6.059 & 1.218 & 7.521 \\
\hline Walking & 2.488 & 0.250 & 1.984 & 0.155 & 2.889 & 3.230 & 6.000 \\
\hline Running & 2.224 & 0.460 & 5.105 & 0.781 & 3.903 & 3.237 & 7.724 \\
\hline $\begin{array}{l}\text { Corrective } \\
\text { gymnastics }\end{array}$ & $10.757^{*}$ & 1.038 & 2.931 & 0.130 & 7.838 & 7.124 & 5.805 \\
\hline Weight loss & 5.340 & 1.187 & 6.730 & 0.130 & 7.282 & 3.565 & $13.334^{*}$ \\
\hline
\end{tabular}

$* p \leq 0.05$ 
A. Olchowska-Kotala, K. Chromik, Education and the prevention of postural defects

at weight loss, $\chi^{2}(1, n=424)=40.563, p=0.001$. Slightly more women than men wanted to participate in the posture correction classes, $\chi^{2}(1, n=423)=3.395, p=0.065$. There were no differences between the men and women in the intention to participate in the remaining extracurricular activities.

\section{Discussion}

Although a majority of the respondents, both female and male, were found to have normal BMI and aboveguideline PA [7], 41\% declared they felt lower back pain. Acute pain in the lumbar spine is very common [1], but considering that this result was found in a group of young individuals, $41 \%$ is a worrying number. This finding suggests the need for introducing interventions in this population.

The present study examined the prevention of postural defects by considering various aspects that may determine healthy posture in sitting and walking, as these are the most frequently performed activities in the course of the day, and using proper running technique, an increasingly popular physical activity among young people. The collected data indicated that information imparting healthy postural habits was most commonly introduced in primary school. Many respondents also indicated their family home as a source of learning proper postural habits. Although proper posture should be established at an early school age [8], not all of the respondents indicated they acquired such knowledge during this period. Thus, due to the high health and economic costs of chronic low back pain [9], education on proper posture habits in everyday activities of life (and preventing spine-related pain) should be continual, from primary school to later educational stages as well as in the workplace [10]. Although not all of respondents declared being taught proper sitting and walking habits or correct running technique, this is not indicative that some schools lacked posturerelated programs. Such information is sometimes conveyed separately, interwoven in other school activities such as physical education classes. Another explanation for these results may also stem from the fact that the respondents did not remember being taught this subject or that not enough emphasis was placed during classes in the prevention of postural disorders.

Not all of the respondents who negatively assessed their body posture wanted to participate in the extracurricular activities, such as corrective gymnastics classes. However, the predictors of the intention to participate in this extracurricular were poor self-assessed posture in women and being overweight in men. The results showed that slightly more women than men wanted to participate in corrective gymnastics. The results also suggested that the predictors of the intention to participate in activities on proper sitting posture were taking little physical activity in men and low back pain in women. Although many of the respondents expressed their in- tention to participate in activities on proper walking posture and proper running technique, none of the analyzed variables were found to determine these intentions. Noteworthy is the fact that a large number of respondents wanted to participate in the suggested activities, indicative that young people do recognize the need to improve body image and work on correcting posture. The age range of this sample (university students) is a time when involvement in physical activity switches from habitual to intentional behavior [11]. Therefore, it would worthwhile to expand current university-level physical education classes and place emphasis on proper postural habits.

One finding that was not surprising was that women were more willing to participate in weight-loss exercises. This has been confirmed in earlier studies, showing higher levels of body dissatisfaction in women than men $[12,13]$ and is a reflection of the social pressure to be slim [14]. Previous studies have indicated that body mass is a significant contributing factor not only to women's body image [15] but also self-esteem [16]. The results of our study indicated that the intention to participate in the suggested posture- and health-related activities among women was higher in those with greater BMI and body dissatisfaction and with a lower opinion of one's attractiveness or posture. Among men, the intention to participate in weight-loss exercises was not associated with BMI but instead body dissatisfaction. The lack of a relationship between the intention to participate in weight-loss exercises and BMI reveals that not all men with above normal BMI wish to participate in such activities. In turn, the number of women who declared their intention to perform weight-loss exercise was much higher than the number of women that who would warrant such exercise as based on their BMI. Nonetheless, the differences between the sexes indicate the need for separate prevention models. In men, this should involve building awareness on maintaining a normal weight to height ratio. Interventions aimed at women should instead concentrate on correcting weight-related misconceptions and introduce psychological skills increasing body satisfaction levels.

The present study has a number of limitations that require addressing. First, it is subject to self-evaluation and recall biases, where respondents may have consciously or unconsciously misreported data. The potential errors of these methods are well-known [17]. Second, the study was correlational in nature, limiting the drawing of any cause-and-effect conclusions.

\section{Conclusions}

Based on the fact that a significant number of the respondents experienced low back pain and declared their intention to participate in extracurricular postureand weight-related activities, additional educational interventions at all levels of education are needed to prevent the onset of postural disorders. These conclusions, 
similar to those presented elsewhere $[18,19]$, point to the need for a multi-disciplinary intervention involving physical education teachers and therapists and include the development of posture-related knowledge, beliefs, and habits and include well-thought-out and planned physical activity.

\section{References}

1. Anderson L., Educational approaches to management of low back pain. Orthop Nurs, 1989, 8 (1), 43-46

2. Calvo-Muñoz I., Gómez-Conesa A., Sánchez-Meca J., Prevalence of low back pain in children and adolescents: a meta-analysis. BMC Pediatrics, 2013, 13, 14, doi: 10.1186/1471-2431-13-14.

3. Dolphens M., Cagnie B., Danneels L., De Clercq D., De Bourdeaudhuij I., Cardon G., Long-term effectiveness of a back education program in elementary schoolchildren: an 8-year follow-up study. Eur Spine J, 2011, 20 (12), 2134-2142, doi: 10.1007/s00586-011-1856-9.

4. Webb T.L., Sheeran P., Luszczynska A., Planning to break unwanted habits: habit strength moderates implementation intention effects on behavior change. Br J Soc Psychol, 2009, 48 (3), 507-523, doi: 10.1348/014466608X370591.

5. WHO, Obesity: Preventing and managing the global epidemic. Report of a WHO consultation World Health Organization Technical Report Series 2001/03/10 ed. WHO, Geneva 2000, 894, 1-253.

6. Biernat E., Stupnicki R., Gajewski A.K., Międzynarodowy Kwestionariusz Aktywności Fizycznej (IPAQ) - Polish version. Wychowanie Fizyczne i Sport, 2007, 51 (1), 47-54.

7. Haskell W.L., Lee I.M., Pate R.R., Powell K.E., Blair S.N., Franklin B.A. et al., Physical activity and public health: updated recommendation for adults from the American College of Sports Medicine and the American Heart Association. Circulation, 2007, 116 (9), 1081-1093, doi: 10.1161/CIRCULATIONAHA.107.185649.

8. Jones G.T., Macfarlane G.J., Predicting persistent low back pain in schoolchildren: a prospective cohort study. Arthritis Rheum, 2009, 61 (10), 1359-1366, doi: 10.1002/ art.24696.

9. Andersson G.B.J., Epidemiological features of chronic low-back pain. Lancet, 1999, 354 (9178), 581-585.

10. Burton A.K., Balague F., Cardon G., Eriksen H.R., Henrotin Y., Lahad A. et al., How to prevent low back pain.
Best Pract Res Clin Rheumatol, 2005, 19 (4), 541-555, doi: 10.1016/j.berh.2005.03.001.

11. Wood W., Tam L., Witt M.G., Changing circumstances, disrupting habits. J Pers Soc Psychol, 2005, 88 (6), 918-933, doi: 10.1037/0022-3514.88.6.918.

12. Ogden J., Mundray K., The effect of the media o body satisfaction: the role of gender and size. Eur Eat Disord Rev, 1996, 4 (3), 171-182, doi: 10.1002/(SICI)10990968(199609)4:3<171::AID-ERV132>3.0.CO;2-U.

13. Olmsted M.P., McFarlane T., Body weight and body image. BMC Women's Health, 2004, (Suppl 1), S5, doi: 10.1186/14726874-4-S1-S5.

14. Monteath S.A., McCabe M.P., The influence of societal factors on female body image. J Soc Psychol, 1997, 137 (6), 708-727, doi: 10.1080/00224549709595493.

15. Algars M., Santtila P., Varjonen M., Witting K., Johansson A., Jern P. et al., The adult body: How age, gender, and body mass index are related to body image. J Aging Health, 2009,21(8),1112-1132, doi:10.1177/0898264309348023.

16. Biro F.M., Striegel-Moore R.H., Franko D.L., Padgett J., Bean J.A., Self-esteem in adolescent females. J Adolesc Health, 2006, 39 (4), 501-507, doi:10.1016/j.jadohealth.2006.03.010.

17. Maughan B., Rutter M., Retrospective reporting of childhood adversity: Issues in assessing long-term recall. J Pers Disord, 1997, 11 (1), 19-33.

18. Wand B.M., Bird C., McAuley J.H., Dore C.J., MacDowell M., De Souza L.H., Early intervention for the management of acute low back pain: a single-blind randomized controlled trial of biopsychosocial education, manual therapy, and exercise. Spine, 2004, 29 (21), 2350-2356.

19. Mendez F.J., Gomez-Conesa A., Postural Hygiene Program to Prevent Low Back Pain. Spine, 2001, 26 (11), 1280-1286.

Paper received by the Editor: May 27, 2014

Paper accepted for publication: June 9, 2014

Correspondence address

Agnieszka Olchowska-Kotala

Zakład Humanistycznych Nauk Lekarskich

Uniwersytet Medyczny we Wrocławiu

ul. Mikulicza-Radeckiego 7

50-367 Wrocław, Poland

e-mail: agnieszkakotala1@gazeta.pl 